Pobrane z czasopisma New Horizons in English Studies http://newhorizons.umcs.pl Data: 26/04/2023 16:47:02

New Horizons in English Studies 3/2018

\title{
LITERATURE
}

@

Ida Marie Olsen

UnIVERSITY OF AGDER, NORWAY

idamarieolsen@gmail.com

\section{Do Androids Have Nightmares About Electric Sheep? Science Fiction Portrayals of Trauma Manifestations in the Posthuman Subject in Frankenstein, Do Androids Dream of Electric Sheep?, and 'Nine Lives'}

\begin{abstract}
This essay explores the contention that posthuman subjects, such as androids, clones, and robots, can experience psychological trauma. The aim of the paper is to examine this notion in three science fiction texts: Mary Shelley's Frankenstein, Philip K. Dick's Do Androids Dream of Electric Sheep?, and Ursula K. Le Guin's short story 'Nine Lives'. What these narratives illustrate is that trauma manifestations can contribute to a disruption of ontological frameworks that maintain categories such as 'human' and 'non-human' as permanent and distinct. As a result, it might be argued that these texts undermine anthropocentrism and invite a reconceptualising around the term 'human', but also around trauma, conventionally understood as a primarily human experience. Science fiction is thereby a significant genre when it comes to questioning anthropocentric perspectives. Using posthuman theory and trauma studies, this essay argues that these three texts portray their respective posthuman subjects as trauma victims, and further that they demonstrate how the experience of trauma carries with it the potential to bridge the gap between human and posthuman through the act of bearing witness to one another's trauma.
\end{abstract}

Keywords: Science fiction, trauma studies, posthumanism, Frankenstein, Philip K. Dick, Ursula K. Le Guin 
Do Androids Have Nightmares About Electric Sheep? Science Fiction Portrayals... 101

\section{Introduction}

The term 'Anthropocene' was popularised by Nobel-winning chemist Paul Crutzen around the turn of the millennium, denoting what many scholars now consider the appropriate name for our current geological epoch. What defines the Anthropocene is how human activity has altered Earth's climate and atmosphere to the extent that humankind must consider itself a direct geophysical force and an incontrovertible influence on the environment (Crutzen, 2002, 23). If this is indeed the case, the 'discovery' of the Anthropocene should serve as the impetus to abandon the notion of human exceptionalism. Humanities research, literary studies included, is required to take this into account. Among the currently expanding fields within the study of literature is trauma studies, committed to exploring literary representations of psychological trauma. Considering the implications of the Anthropocene, however, one might argue that the field's focus is highly anthropocentric. This is perhaps not surprisingly also the case for most psychoanalytic criticism, as we tend to think of the mind, the unconscious, and emotional intelligence as something uniquely and definingly human. How can a robot, for instance, be capable of repressing traumatic memories? This is hardly something we can imagine in today's technologies, despite the rapid development of computers that are becoming increasingly mind-like. However, these are scenarios that science fiction texts have already been exploring for decades. Scholars should therefore discard what Roger Luckhurst (2014) has described as a 'high cultural suspicion of SF', which perhaps has prevented science fiction texts from being fully explored in the past (5), and should devote more attention to the issues that sci-fi has raised and to how the genre can contribute to dissolving the foundations of anthropocentric perspectives.

A small amount of research has already examined the notion of posthuman trauma to a certain extent. In his article 'Posthuman Wounds' (2014), Tony M. Vinci argues that the human characters of Philip K. Dick's novel Do Androids Dream of Electric Sheep? (1968) practice a form of trauma deferment by using androids and animals as scapegoats, and thus uphold an ontological framework that promotes human exceptionalism (93). Vinci also briefly speculates about the androids' potential to experience trauma themselves: 'what would it mean if the android could indeed be possessed by the traumatic event while also fully inhabiting the traumatic moment? In other words, what if the android were not only "witnessing" human events, but experiencing its own trauma as well?' $(2014,97)$. This is an intriguing question, and one which will serve as the main focus of this essay. Whereas Vinci's article is primarily interested in human trauma, this essay seeks to elaborate on posthuman trauma by examining various sci-fi narratives that feature traumatised posthuman subjects, and to draw attention to the different ways in which these traumas manifest. The essay aims to consider the Creature from Mary Shelley's Frankenstein (1818), the androids featured in Philip K. Dick's Do Androids Dream of Electric Sheep?, and Kaph, the clone from Ursula K. Le Guin's short story 'Nine Lives' (1969). By synthesising trauma studies with theories loosely centred around posthumanism, the essay will show that the above-mentioned texts 
suggest that manufactured posthuman subjects are indeed able to experience trauma in different manners, and that this contributes to a blurring of the boundaries between machines and humans, thus undermining anthropocentrism. Further, one might argue that the texts also illustrate how trauma in the posthuman subject provides opportunities for humans to bear witness to the Other's suffering, and hence the experience of trauma establishes a platform for encounters where the human's fear of the posthuman Other transforms into understanding and compassion. This is also the outcome when both human and posthuman are victims of trauma, and are able to connect in their mutual experience, as some of the texts show.

\section{Trauma and Technology}

In the past, trauma studies have been concerned with topics such as political conflict, war, violence, terror, and the Holocaust. With regard to the relationship between trauma and technology, one might argue that the latter has indirectly been regarded as contributing to psychological trauma, although there is much potential in focusing more closely on the role of technology in trauma studies. Indeed, Roger Luckhurst (2005) has advocated the necessity for more research incorporating science fiction texts into the field (5). Luckhurst, in his tracing of the cultural history of science fiction, asserts how technology has conventionally been regarded as a cause of psychological trauma $(2005,27)$. Walter Benjamin, for instance, famously paints a picture of the modern urban experience where crowds, cameras, films, and traffic cause the individual to experience 'a series of shocks and collisions' (Benjamin 2006, 27). Modern technology has therefore been seen as inherently traumatic for the human individual, and has been understood to cause trauma. This is perhaps also apparent in Freud's famous railway accident example, where he illustrates how accidents may lead to symptoms of trauma; what causes the traumatising accident is the technology of the railway. It may be suggested, however, that the development of technology has come so far that it might be time to reverse our thinking about the trauma/technology relationship. An idea that may be considered is that instead of technology causing human trauma, we are now the ones who traumatise technology. What if technology, in the form of computers and robots, has evolved to the point where it possesses the ability to become traumatised? This trajectory of thought is one that ought to be considered in an attempt to debunk anthropocentrism and to investigate and broaden the categories of 'trauma', 'human', and 'posthuman'.

Upon closer inspection, these scenarios are not as bizarre as they sound because the fact is that mind-like computers are already in the process of construction. Robots and computers are now functioning with such complexity and sophistication that they are close to replicating human characteristics and abilities. In his overview of the possibilities of cognitive computing and cognitive systems, Ahmed K. Noor (2015) explains that these new computer systems are designed to work like the human brain, or rather, the human mind. 'Deeper biological understanding of how the brain worked allowed 
Do Androids Have Nightmares About Electric Sheep? Science Fiction Portrayals... 103

scientists to build computer systems modelled after the mind, and most importantly to build a computer that could integrate past experience into its system', Noor states (76). Through developments in the incorporation of neural networks into computers, 'researchers argue that the brain is a type of machine, and can therefore potentially be replicated' (Noor 2015, 76). The notion of technological adaptation of human abilities and mental properties has, however, been introduced decades earlier, as illustrated by, for instance, the anthology Android Epistemology (1995), edited by Kenneth M. Ford, Clark N. Glymour, and Patrick J. Hayes. The anthology contains Herbert A. Simon's article 'Machine as Mind', which presents the thesis that the acquisition of a mind is achievable for computers because the human brain is replicable: 'the materials of thoughts are symbols - patterns, which can be replicated in a great variety of materials (including neurons and chips)' $(1995,25)$. Simon further criticises sceptics of this idea for having a romanticised understanding of the human mind $(1995,38)$. Both Simon's and Noor's work, then, demonstrate that posthuman intelligence is not located in the realm of distant future, and that today's advancements in cognitive computers underscore the necessity of reflection around these issues. If computational machines are becoming intelligent and capable of storing memories, then our notion of the psyche needs to be altered to include posthuman subjectivity. As Noor points out, trauma in computers, robots, and androids, may soon become an actuality, and we should therefore dismiss the thought of trauma as a uniquely human experience.

This is where literature, and especially science fiction, can provide valuable knowledge. Luckhurst (2014) has argued that the study of science fiction within a trauma studies framework can lead to significant insights into the trauma concept because the genre 'dismantle[s] any recognizable human subject in challenging ways [...] as imagined futures outgrow the psychodynamic frameworks that dominate conceptions of cultural trauma' (159). However, Luckhurst does not elaborate on how this expanded trauma theory, where one incorporates posthuman subjectivity, would be configured. He points to texts such as Greg Egan's 'Reasons to be Cheerful' (1999) and Charles Stross' novel Accelerando (2005), where subjectivity has been completely altered through capacities for simulation and direct neurological interference, and Luckhurst argues that 'these visions challenge us to address the rapid development of new scientific understandings that are likely to reconceptualise notions of trauma in the very near future' $(2014,166)$. Although, as Luckhurst states, there is a necessity to reconceptualise trauma, one might still argue that 'traditional' trauma theory can serve as a beneficial angle from which to consider the posthuman subject, as many of the discussions provided by, for instance, Freud and Cathy Caruth are still highly relevant in an encounter with science fiction.

Drawing on psychoanalysis, post-structuralism, and psychology, literary trauma theory developed in the later decades of the twentieth century, especially following the introduction of the PTSD diagnosis. The field draws major inspiration from Freud, one of the first philosophers to discuss trauma, although he revised his opinion about the nature of the concept several times. In Beyond the Pleasure Principle (1920) and Moses and Monotheism (1939), Freud debates symptoms, such as the nightmares of 
soldiers after the war, in what he identifies as trauma victims. Cathy Caruth (1996), who is one of the leading trauma theorists today, interprets Freud's definition of trauma as 'an event that $[\ldots]$ is experienced too soon, too unexpectedly, to be fully known and is therefore not available to consciousness until it imposes itself again, repeatedly, in the nightmares and repetitive actions of the survivor' (4). Discussing the trauma of accidents, Caruth argues that the accident:

does not simply represent the violence of a collision but also conveys the impact of its very incomprehensibility. What returns to haunt the victim [...] is not only the reality of the violent event but also the reality of the way that its violence has not yet been fully known $(1996,6)$.

Trauma therefore revolves mainly around the individual's inability to comprehend, or process, the traumatising event. This might have some interesting implications in light of artificial intelligence, which, like the human mind, would be engaged in an act of processing. Michelle Balaev (2008) similarly interprets trauma as becoming 'unrepresentable due to the inability of the brain, understood as the carrier of coherent cognitive schemata, to properly encode and process the event' (151). The terminology here therefore suggests some evident links between the trauma experience and machine intelligence. Typical symptoms of trauma have been listed by Luckhurst (2008), drawing on the official diagnostic manual from the American Psychiatric Association, and include flashbacks, nightmares, avoidance of thoughts and feelings, loss of temper control, and hyper-vigilance (1). These are symptoms that we can identity in the posthuman trauma victims depicted in the texts this essay will be examining.

\section{Monstrous Wounds: Primal Trauma and Parental Rejection in Frankenstein}

Several critics have noted that Mary Shelley's Frankenstein may have been a manifestation of the author's own traumatic experiences. Mark A. Rubenstein (1976) emphasises how the novel was influenced by Shelley's loss of her mother, as well as the death of Shelley's child shortly after his birth. These are aspects of trauma related to parenthood, family, and birth - significant themes that can contribute to an understanding of the traumas located in the novel. In the backdrop of the novel's horror, trauma does, indeed, play a significant part. Examining the Creature's psyche in light of trauma will reveal how the novel portrays a posthuman form of trauma while also advocating the need for this trauma to be acknowledged. The majority of psychoanalytic readings (such as Rubenstein's and Sherwin's (1981)) have been devoted to examining Victor's psyche, when in reality the Creature's psyche is equally important for understanding the novel. The Creature in Frankenstein has typically been attributed to the role of perpetrator, murderer, and antagonist, and hence he is also known as 'the Monster'. Yet, by allowing the Creature to express his grief and by giving voice to his version 
Do Androids Have Nightmares About Electric Sheep? Science Fiction Portrayals... 105

of the story, the novel clearly invites sympathy for the Creature and implies that his monstrosity derives from Victor's failure in his role as a 'parent'. The novel thus urges the reader to consider the Creature more as a victim rather than as perpetrator, and, considering Victor's side of the story, presents these categories as fluid and unstable.

There are several hints in the novel that the Creature does experience trauma and is capable of emotional reactions. As we learn from Victor's account, the Creature is made from organic materials, both human and animal, and is somehow brought to life by Victor trying to 'infuse a spark of being into the lifeless thing' (Shelley 2017, 41). We can therefore assume that the Creature is humanoid, though not entirely human. The narrative reveals that he has highly developed cognitive abilities and that he experiences strong emotions. This becomes particularly evident in the novel's ending scene, where the Creature talks about his 'wounds' (Shelley 2017, 87), which is the translation of the word 'trauma' in Greek. He appears traumatised, speaking of his 'burning miseries' and the 'agonies which consume [him]' (Shelley 2017, 186-87). If not directly showing symptoms of trauma, the Creature certainly experiences strong emotions, generated by the memories he has stored. It might also be suggested that the Creature exhibits more empathy and emotions than humans in many instance, as illustrated, for example, by his vegetarian diet: 'my food is not that of man: I do not destroy the lamb and the kid, to glut my appetite; acorns and berries afford me sufficient nourishment' (Shelley 2017, 121). The Creature also experiences empathy towards other people through, for instance, his ability to observe the daily lives of the De Lacey family, listen to their stories, recognise their emotions, and assist them. As will also be the case with Do Androids Dream of Electric Sheep?, empathy is one of the main 'symptoms' of being human in Dick's novel.

The main source of the Creature's trauma, one might argue, is, in fact, his own birth - a traumatising experience that is reinforced by Victor's immediate rejection. Interestingly, this is reminiscent of what many psychoanalysts, for instance, Freud and Wilfred Bion, theorise about birth in itself as a traumatic occurrence for the infant. Whereas Freud explains primal trauma in terms of how the infant loses connection with the mother, Wilfred Bion sees it as 'an inevitable part of birth, because a baby is born with very limited ability to process its perinatal sense of impressions, which it will inevitably find overwhelming' (Crago 2016, 12). Bion's picture of primal trauma seems very similar to what the Creature experiences during the early moments of his life, when he describes his first memories as 'confused and indistinct' (Shelley 2017, 83). Furthermore, he states 'a strange multiplicity of sensations seized me, and I saw, felt, heard, and smelt, at the same time', as if he cannot process what is happening (Shelley 2017, 83). The birth of the Creature is made increasingly traumatic by Victor's abandonment of his creation, and thus he prevents any form of contact or communication between the two from taking place. Shortly after Victor has fled the scene of the birth, the Creature comes into Victor's bedroom, obviously seeking contact, with 'one hand [...] stretched out' and muttering 'some inarticulate sounds' (Shelley 2017, 42-43). The Creature is therefore portrayed like a newborn overwhelmed by sense impressions. 
The circumstances of the Creature's birth become the recurring trauma that continues to haunt him throughout the story, as he struggles to comprehend Victor's rejection: 'am I not alone, miserably alone? You, my creator, abhor me' (Shelley 2017, 81). Paul Sherwin has similarly discussed the Creature's experience of rejection and exclusion as catastrophic, asserting that:

the Creature's utmost desire is that another reciprocate his need for sympathetic relationship, and even after he becomes searingly conscious of his exclusion from the human community and begins to objectify the negativity he arouses in others, we recognize that his aggression is a by-product of disintegration, not an innate drive that has been cathartically unbound $(1981,890)$.

The Creature's experience of his own exclusion therefore leads him to kill his victims. It is evident that his aggressive actions can be traced back to his trauma.

Both Victor Frankenstein and Walton become witnesses to the Creature's trauma. However, they always seem to be in disbelief, refusing to acknowledge it fully and to accept the Creature's 'humanity'. As will be shown at the end of this essay, the act of bearing witness to another's trauma is of major importance in Le Guin's short story, as the text demonstrates that human recognition of the posthuman's ability to become traumatised can lead to successful encounters between human and humanoid. In Frankenstein, both Victor and Walton fail at this recognition. Walton admits to feeling empathy for the Creature at first seeing him and hearing his side of the story when the two meet following Victor's death. 'I was at first touched by the expressions of his misery', Walton states, after having observed the Creature with 'a mixture of curiosity and compassion' (Shelley 2017, 184-85). But when Walton recalls Victor's version of the tale, his emphatic response changes into rage and 'indignation' (Shelley 2017, 185). What Walton does not comprehend is that the Creature clearly suffers from some form of trauma and is desperate for the humans to acknowledge this. However, the humans' narrow view of the psyche and their belief in human exceptionalism is too strong for this to happen, and as a result, the story becomes a tragedy for both Victor and the Creature, a human and a posthuman. Frankenstein thus becomes an important example of how much 'damage' artificial intelligence can do if humans do not acknowledge the full extent of their existence, their inner lives, and their potential to store memories, experiences, and process these episodes. In this way, the novel makes a significant contribution to posthumanism, particularly as it sheds light on the posthuman subject's ability to become traumatised.

\section{Android Suffering: Trauma as Catalyst for Non-Anthropocentric Ontologies in Do Androids Dream of Electric Sheep?}

Philip K. Dick's novel Do Androids Dream of Electric Sheep? is concerned with the boundaries between human and posthuman, perhaps to an even greater extent than Frankenstein. In its attention to these borders, trauma becomes a significant motif. The 
Do Androids Have Nightmares About Electric Sheep? Science Fiction Portrayals... 107

novel depicts a post-apocalyptic world where the majority of the human population has emigrated to Mars. Humanoid androids have been created, first as a form of war-technology, so-called 'freedom fighters', but now functioning as servants for humans who emigrate. The job of protagonist Rick Deckard is to 'retire' those androids who have escaped to Earth, where their presence is illegal. This is something he accomplishes through performing an empathy test on the androids, as the only way to distinguish them from humans is to prove their alleged inability to empathise. As the narrative progresses, this distinction between human and android gradually falters. Commenting on Dick's fiction in general, Roger Luckhurst (2005) states that the 'protagonists find their locations in time and space subject to a bewildering disorder, as the fabric of reality distends, revealing a jerry-built artifice on the verge of collapse' (107). Not only is this 'bewildering disorder' a major ontological trauma for the human characters in Do Androids Dream, but this is also the case for the androids. In the universe of the novel, humans are considered 'real' and superior to the artificial androids in the same manner as 'real' animals are seen as superior to electric ones. As a result, the androids are consistently confronted with social conventions which assert their artificiality, as the characters we know to be androids continue to be reminded that they are not human, even though everything that happens in the narrative suggests that the human/android dichotomy is false. Furthermore, as Tony Vinci points out, if android trauma is considered a valid narrative of pain, it will threaten to revise the distinction between real and artificial $(2014,95)$. Since the novel indicates that android trauma is real, this is one of the main ways in which Dick initiates a broadening of the 'human' concept and introduces posthuman trauma as a valid experience.

The novel demonstrates this posthuman trauma in several ways. The most significant scene of android traumatisation is when Rachael, a Nexus-6 type android, discovers Deckard's plans to retire Pris, an android who shares her physical features. Rachael is clearly upset and distracted by Deckard's revelation: 'she had turned pale and her voice shook. All at once she had become exceptionally unsteady' (Dick 1999, 159). The scene demonstrates how Rachael feels empathy for Pris, and possibly for the other androids as well, something she confirms when Deckard suggests that she feels empathy (Dick 1999, 161). In spite of the fact that Rachael may simply be simulating her empathetic response, the novel later implies that Rachael also has feelings and empathy for Deckard. Indeed, N. Katherine Hayles's interpretation of Rachael's character is that:

Rachael's strategy implies that she feels empathy for her fellow androids, giving lie to the government's position that androids feel no loyalty to each other. If she can care for her fellow androids, we may wonder if she also cares for Deckard, as she claims when she tells him that she loves him (173).

In a manner highly reminiscent of the Creature's murders in Frankenstein, Rachael proceeds to murder Deckard's goat after he has ventured to retire the remaining androids. Rachael's unpredictable behaviour, it may be suggested, is symptomatic of her trauma. Rachael is traumatised by Deckard's ultimate belief in her artificiality, which he 
particularly demonstrates in how abruptly he decides to kill her but changes his mind again. Another contributing cause for Rachael's trauma could of course also be Deckard's retirement of her fellow androids, which again underscores Rachael's empathy. Regardless of Rachael's motives, the act of murdering Deckard's goat demonstrates Rachael's posthuman trauma, thereby both undermining the ontological framework that the Do Androids Dream society rests on and confirming the actuality of posthuman trauma.

\section{'The Strangeness of the Stranger': Encountering the Other Through Trauma in 'Nine Lives'}

Ursula K. Le Guin's short story 'Nine Lives' depicts two humans stationed to work on a uranium mining project on the atmospherically hostile planet Libra. As the story begins, the men, Pugh and Martin, are joined by a crew of superhuman clones who appear to share an exceptionally close bond. The expedition transforms into a traumatic experience for one of the clones, Kaph, when his nine 'siblings' die in the impact of an earthquake. What is interesting about this story is the trauma that Kaph clearly suffers from following this event. It is evident that the episode manifests as a completely posthuman form of trauma because of the close connections that the clones share. What is significant, too, is the way in which this posthuman trauma leads to an encounter and a mutual understanding between human and humanoid. Le Guin's story therefore highlights the importance of trauma as a mutual experience platform for a successful human/humanoid confrontation, and demonstrates that trauma can contribute to breaking down human perceptions of distinct boundaries between human and posthuman, much like in Dick's novel. This theme is also emphasised by Le Guin's choice of setting; the stage where the trauma unfolds is itself portrayed as a traumatised place. The opening of the narrative describes the planet Libra in the following manner: "she was alive inside but dead outside [...]. Underneath, in the black corridors, the halls beneath the skin, there were crepitations in darkness, ferments, chemical nightmares that went on for centuries' (Le Guin 2010, 453) (my italics). This resonates with typical trauma symptoms such as nightmares, and one wonders whether Le Guin intentionally draws on trauma as a theme in this story.

Like the Creature in Frankenstein and Rachael in Do Android Dream, Kaph is traumatised. His trauma arises from a distinct event: the loss of his siblings in the unexpected event of an earthquake. This form of trauma, which stems from a sudden and incomprehensible incident, seems to correspond to Freud's understanding of accident trauma. As previously mentioned, Freud imagines a person surviving a train accident unharmed, but with symptoms of trauma manifesting in the weeks after the accident. 'He develops a series of grave physical and motor symptoms, which one can ascribe only to his shock or whatever else happened at the time of the accident. He has developed "traumatic neurosis"', Freud writes $(1939,119)$. Similarly, Kaph is in shock but physically unharmed when Pugh and Martin discover him at the site of the earthquake. 
Do Androids Have Nightmares About Electric Sheep? Science Fiction Portrayals... 109

He experiences seizures and choking for a long period of time after the accident, and when the seizures finally subside he appears apathetic, silent, and 'staring into a darkness that was not there' (Le Guin 2010, 468). Pugh and Martin speculate on whether Kaph is experiencing the deaths of the nine other clones. 'They were all of him, he is all of them. They died, and now he's dying their deaths one by one', they state (Le Guin 2010, 467). The full extent of Kaph's trauma begins to dawn on Pugh and Martin as they continue to observe him. Additionally, what is noticeable about the two men is that they are afraid of Kaph, believing him to be unpredictable and capable of killing them. This eerie situation echoes the uncanniness at the beginning of the story when the humans meet the clones for the first time. Pugh and Martin are uncertain of what to make of the ten superhumans, and their scepticism towards them strengthens the distinct categories of 'natural' human and clone. Kaph's unprocessed trauma, like the Creature's trauma in Shelley's novel, therefore poses a threat to the humans (or at least, this is what the humans believe), and the story hints at the fact that the posthuman's ability to experience trauma should be acknowledged and dealt with by humans.

What happens at the end of the short story, however, changes the men's rigid perceptions of the human category, and they become more attuned to and at ease with the posthuman. This transformation takes place through Kaph and the men witnessing each other's trauma. Towards the close of the narrative, both Pugh and Martin experience traumas of their own as Martin is caught in the centre of an earthquake and Pugh sets out to rescue him. The situation causes Kaph to comprehend the two men's affection for one another. The subsequent talk between Pugh and Kaph, which serves as the story's ending scene, clearly alters the situation for Kaph: 'his face was changed, as if he were glimpsing something he had not seen before; his voice too was changed' (Le Guin 2010, 475). What Kaph now sees is Owen Pugh, 'the thing he had never seen before [...] the stranger who held his hand out in the dark' (Le Guin 2010, 476). This scene can serve as an instance of how trauma can lead to an understanding with regard to the Other. This is something Cathy Caruth also emphasises in Unclaimed Experience (1996), where she argues that one's own trauma 'is tied up with the trauma of another' and that 'trauma may lead, therefore, to the encounter with another, through the very possibility and surprise of listening to another's wound' (8). This, one might argue, is exactly what 'Nine Lives' wishes to convey. The 'strangeness of the stranger' (Le Guin 2010, 455), particularly in a posthuman context, becomes less strange when it is recognised that both human and posthuman may suffer from trauma, and that this carries with it the potential for encounters and mutual understandings.

\section{Conclusion}

To conclude, the science fiction genre is invaluable in helping us abandon the anthropocentric worldview that has contributed to the advent of the Anthropocene. As shown here, one way that sci-fi texts achieve this is by illustrating that trauma is not 
a uniquely human experience, but is also potentially experienceable by posthumans such as humanoid creatures, androids, and clones. Mary Shelley's novel highlights the importance of human perceptibility to the needs and symptoms of a traumatized posthuman creation in order to prevent destructive behaviour from taking place. Do Androids Dream also demonstrates how androids have the potential to become trauma victims, although humans do not 'allow' them to. This in itself is traumatic for the androids, and in Rachael's character we clearly observe symptoms of human-like trauma. Finally, 'Nine Lives' is an example of how trauma can lead to reconciliation between human and posthuman, or human and Other, as theorized by Cathy Caruth. Through shared trauma, a successful encounter between Pugh, Martin, and Kaph ensues, and the strangeness of the Other becomes familiarised and safe. What these narratives have in common is their undermining of the rigid boundaries between human and non-human through the use of trauma as motif. Ultimately, all three narratives demonstrate that in a world of accelerating technological development, humans cannot hold on to the myth of anthropocentrism, but must accept the existence of the posthuman.

\section{References}

Balaev, Michelle. 2008. 'Trends in Literary Trauma Theory'. Mosaic: An Interdisciplinary Critical Journal 41, no. 2: 149-166. http://www.jstor.org/stable/44029500.

Benjamin, Walter. 2006. 'On Some Motifs in Baudelaire'. In Selected Writings, vol. 4: 1938-40, edited by Howard Eiland and Michael W. Jennings, 313-355. Cambridge: Harvard University Press.

Caruth, Cathy. 1996. Unclaimed Experience: Trauma, Narrative, and History. Baltimore and London: The Johns Hopkins University Press.

Crago, Hugh. 2016. The Stages of Life: Personalities and Patterns in the Human Emotional Development. Abingdon and New York: Routledge.

Crutzen, Paul. 2002. 'Geology of Mankind'. Nature 415, no. 1: 23.

Dick, Philip K. 1999. Do Androids Dream of Electric Sheep?. London: Orion Books.

Hayles, N. Katherine. 1999. How We Became Posthuman: Virtual Bodies in Cybernetics, Literature, and Informatics. Chicago and London: The University of Chicago Press.

Le Guin, Ursula K. 2010. 'Nine Lives'. In The Wesleyan Anthology of Science Fiction, edited by Arthur B. Evans, Istvan Csicsery-Ronay Jr, Joan Gordon, Veronica Hollinger, Rob Latham, and Carol McGuirk, 452-76. Middletown: Wesleyan University Press.

Luckhurst, Roger. 2005. Science Fiction. Cambridge and Malden: Polity Press.

-. 2008. The Trauma Question. Abingdon and New York: Routledge.

—. 2014. 'Future Shock: Science Fiction and the Trauma Paradigm'. In The Future of Trauma

Theory: Contemporary Literary and Cultural Criticism, edited by Gert Buelens, Samuel Durrant, and Robert Eaglestone, 157-67. Abingdon and New York: Routledge.

Noor, Ahmed K. 2015. 'Potential of Cognitive Computing and Cognitive Systems'. De Gruyter 5, no. 1: 75-88. doi:10.1515/eng-2015-0008. 
Pobrane z czasopisma New Horizons in English Studies http://newhorizons.umcs.pl Data: 26/04/2023 16:47:02

Do Androids Have Nightmares About Electric Sheep? Science Fiction Portrayals... 111

Rubenstein, Marc A. 1976. "My Accursed Origin”: The Search for the Mother in "Frankenstein"'. Studies in Romanticism 15, no. 2: 165-94. doi:10.2307/25600007.

Shelley, Mary. 2017. Frankenstein, or the Modern Prometheus: Annotated for Scientists, Engineers, and Creators of All Kinds, edited by David H. Guston, Ed Finn, and Jason Scott Robert, Cambridge and London: The MIT Press.

Sherwin, Paul. 1981. 'Creation as Catastrophe'. PLMA 96, vol. 5: 883-903. doi:10.2307/462130.

Simon, Herbert. 1995. 'Machine as Mind'. In Android Epistemology, edited by Kenneth M. Ford, Clark Glymour, and Patrick J. Hayes, 23-40. Cambridge and London: The MIT Press.

Vinci, Tony M. 2014. 'Posthuman Wounds: Trauma, Non-Anthropocentric Vulnerability, and the Human/Android/Animal Dynamic in Philip K. Dick's Do Androids Dream of Electric Sheep?'. The Journal of the Midwest Modern Language Association 47, no. 2: 91-112. http://www.jstor.org/stable/44066191. 